\title{
A FUNDAÇÃO DE BELÉM E O DISCURSO EUROCENTRADO 400 ANOS DEPOIS
}

\section{The Belém foundation and the eurocentrated discourse 400 years later}

\section{La fundación de Belém y el discurso eurocentrado 400 años después}

\author{
Moisés Sarraf \\ Jornalista e doutorando em Memória Social (Linha de pesquisa - Memória e Patrimônio) pela \\ Universidade Federal do Estado do Rio de Janeiro (PPGMS-Unirio) \\ moises.sarraf@gmail.com
}

Ivânia dos Santos Neves Professora Titular da Universidade Federal do Pará (UFPA), onde atua no Instituto de Letras e Comunicação (Graduação) e no Programa de Pós-Graduação em Letras

(Mestrado/Doutorado). ivanian@uol.com.br

\section{Resumo}

Este artigo busca caracterizar o discurso sobre o aniversário de 400 anos de Belém a partir de suas materialidades na imprensa da capital paraense. Para isso, optamos por analisar discursivamente o conteúdo jornalístico do portal G1 Pará, veículo que dedicou uma página exclusiva aos festejos referentes ao aniversário de Belém em 2016. Recortamos, então, enunciados midiáticos, procurando pontes que lhes vinculem àqueles publicados nos jornais impressos do ano de 1966, "O Liberal" e "Folha do Norte", quando foi comemorado o aniversário de 350 anos da cidade. O artigo tem como referencial teórico-metodológico a análise do discurso de linha foucaultiana, apoiando-se, para a compreensão de nosso objeto empírico, em categorias das teorias do jornalismo.

Palavras-chave: Belém. Jornalismo. Análise do discurso.

\begin{abstract}
This paper aims to explain the discourse about the 400th Belem's aniversary acoording to content published on the press. Thus, we choose to analyse discursively stories of the website G1 Pará, vehicle that created an exclusive hotsite for the jornalistic articles of de Belém's aniversary in 2016. This work includes the analyses seeks bridges between the year of 2016 and 1966, when two newspapers, "O Liberal" and "Folha do Norte", published stories about the 350th citie's anniversary. The paper has a framework based in the discourse analyses in the perspective of Michel Foucault and using in the the concepts of journalism theory to understand our research subject.
\end{abstract}

Key words: Belém. Journalism. Discourse analyses. 


\section{Resumen}

Este artículo busca caracterizar el discurso sobre el aniversario de 400 años de Belén a partir de sus materialidades en la prensa de la capital paraense. Para ello, optamos por analizar discursivamente el contenido periodístico del portal G1 Pará, vehículo que dedicó una página exclusiva a los festejos referentes al aniversario de Belén en 2016. Recortamos, entonces, enunciados mediáticos, buscando puentes que les vincule a aquellos publicados en los periódicos impresos del año de 1966, "El Liberal" y "Folha del Norte", cuando se conmemoró el aniversario de 350 años de la ciudad. El artículo tiene como referencial teóricometodológico el análisis del discurso de línea foucaultiana, apoyándose, para la comprensión de nuestro objeto empírico, en categorías de las teorías del periodismo.

Palabras clave: Belém. Periodismo. Análisis del discurso.

\section{INTRODUÇÃO}

Nossas reflexões sobre as cidades panamazônicas e sua multiplicidade étnica se iniciam com os debates em torno do tema "aniversário de 400 anos de Belém”, acontecimento veiculado nos meios de comunicação e pouco debatido a respeito dos sentidos atribuídos à comemoração por diferentes grupos na cidade. $\mathrm{O}$ tema emergiu à medida que o quadragésimo aniversário da cidade se aproximou, em especial durante a campanha eleitoral de 2012. Em meio aos debates, nos discursos dos candidatos, começou-se a traçar o festejo do aniversário, a ser comemorado em 2016, como um marco a se impor na história da capital paraense. O vencedor do pleito, portanto, conduziria os festejos do quarto centenário - seria um nome a entrar para a História.

Com a eleição do prefeito Zenaldo Coutinho (PSDB), a prefeitura de Belém, em parceria com a gestão do governador Simão Jatene (PSDB), tornou-se o principal agente a traçar uma programação oficial em comemoração aos 400 anos. Junto do poder público, o meio empresarial passou a reposicionar suas marcas publicitárias em função da comemoração. Universidades e outros centros de ensino e pesquisa realizaram debates a respeito do assunto. $\mathrm{Na}$ mídia, o tópico passou a ser cada vez mais frequente. A primeira medida oficial, nesse contexto, foi a formação, em março de 2014, da comissão dos 400 anos, grupo que criaria e dirigiria a comemoração oficial do aniversário de Belém. Apenas em outubro de 2015 foi anunciada a segunda medida referente aos festejos: o lançamento da programação oficial, conjunto de ações que incluía 63 eventos, distribuídos no decorrer de 13 meses.

$\mathrm{Na}$ pesquisa que origina este artigo, começamos a visualizar a emergência de enunciados sobre o aniversário da cidade e sua diversidade étnica, ou melhor, sua subestimada diversidade étnica no discurso midiático. Consolidada uma hipótese inicial de que populações 
afrobrasileiras e indígenas foram silenciadas na comemoração dos 400 anos, tomando como referência enunciados veiculados na mídia - do rádio à tevê, do jornal impresso à web -, passamos a nos perguntar: como se construiu esse discurso que enaltece as origens portuguesas de Belém em detrimento de outros grupos que constituíram e constituem a cidade?

Antes de nos debruçarmos propriamente sobre nossas categorias teóricas e a análise em si, devemos fazer algumas considerações sobre o significado da comemoração de aniversários na Amazônia. A cidade de Belém, assim como uma série de outras cidades no Brasil e de outros países da América Latina, realiza anualmente um conjunto de festejos em comemoração aos seus aniversários. Esse aniversário vem sendo comemorado no dia 12 de janeiro de 2016. A data, por sua vez, tem como referência a presença portuguesa em uma região que viria a ser conhecida no decorrer do tempo por diversos títulos, como Feliz Lusitânia, Cidade do Pará, Santa Maria de Belém do Grão-Pará e, então, Belém. Para Neves (2015), portanto, a comemoração anual do aniversário é uma homenagem ao processo de colonização europeia na Amazônia.

A comemoração desta data, proposta por alguns setores da sociedade local representa, sem dúvida, uma homenagem ao processo de colonização europeia na região. Diferentes sujeitos construíram diferentes discursos para falar sobre a cidade e não foi um processo pacífico, nem igualitário, pelo contrário, foi marcado pelo silenciamento das memórias indígenas e africanas, pela imposição da língua portuguesa e da arquitetura colonial. Não haveria, portanto, um paradoxo entre esta comemoração agenciada pelo poder público e a pluralidade étnica da cidade? (NEVES, 2015, p. 27)

Ainda que não seja o foco deste artigo, cabe acrescentar que, também emergem em nossas análises, recentes regularidades do citado processo em outras cidades amazônicas. Percebemos, então, que a comemoração desses aniversários, a partir de um padrão eurocentrado, não ocorre só em Belém, mas em cidades como São Luís (MA), capital que comunga de um passado de colonização semelhante ao da capital paraense. E, a partir dessa constatação, a que chamamos de formas oficiais de se comemorar (NEVES; SARRAF, 2017, p. 733), partimos para a construção de tais discursos:

Tais formas oficiais incluem alguns elementos, como a intersecção discursiva entre Estado e meios de comunicação ao enunciar o aniversário das cidades. Esse formato de se comemorar tem, ainda, como característica a atualização do processo de colonização da Amazônia como marco fundacional das cidades da região. Ao determinarmos essas formas oficiais de se comemorar, a partir da memória portuguesa, nos perguntamos: há outros meios de se comemorar? Considerando a diversidade étnica que compõe a formação das cidades amazônicas, a partir da presença indígena, 
muito anterior à chegada portuguesa, tanto em Belém quanto em São Luís, a resposta é sim. Considerando o tráfico negreiro, que trouxe à Amazônia africanos escravizados a partir do século XVIII, a resposta é sim.

Situada na foz do rio Pará, Belém, por sua posição, foi um entreposto estratégico durante séculos, desde o início da colonização portuguesa, passando pelos diversos ciclos econômicos orientados por fatores externos à região amazônica. Cidade de 1,4 milhão de habitantes, cuja região metropolitana alcança cerca de 2,2 milhões de moradores, é capital do Pará, mais populoso estado da região amazônica, com 7,5 milhões (Censo, 2010). Com uma economia baseada no setor de comércio e serviços, a cidade recebe investimentos dos segmentos industriais do interior do Estado, como o agropecuário, madeireiro e mineral.

Para verticalizar a análise, nosso olhar se voltou a 50 anos antes, quando, em 1966, a cidade oficial - o Estado, o empresariado e outros atores sociais - comemorou o aniversário de 350 anos da capital paraense, manifestação que se situa em certa memória coletiva (HALBWACHS, 2013), entendida como um saber e uma lembrança, um conhecimento atual do passado que se constrói coletivamente. Os aniversários de 400 e 350 anos, então, começaram a se construir, analiticamente, no campo da memória discursiva (PÊCHEUX, 1997), um espaço simbólico de muitos sentidos em que se encadeia a disputa de interpretações para acontecimentos presentes ou passados. Ficaram evidentes as vinculações entre enunciados veiculados na imprensa de 1966 e de 2016 e suas condições de emergência. $\mathrm{Na}$ pesquisa, tomamos como objeto de análise sites e jornais impressos, que produziram rico acervo sobre aniversários de Belém. Procuramos identificar as relações de poder em que os sujeitos e as organizações mais visibilizadas estavam envolvidas, bem como dos sujeitos à margem do processo.

No segundo item do artigo, intitulado "O método arqueológico nas redes de memória em Belém", vamos apresentar nosso aporte teórico-metodológico a partir de conceitos foucaultianos como discurso, enunciado e condições de possibilidades históricas - dialogando com um conjunto de regras discursivas que possibilitam certa comemoração do aniversário. Por fim, no item “Análises e resultados: vinculações do discurso midiático de 1966 a 2016", apresentamos as materialidades midiáticas analisadas, bem como pontes e intersecções visualizadas entre as comemorações, regularidades e dispersões que compõem os discursos sobre os dois momentos históricos e o processo de atualização de enunciados coloniais. 


\section{O MÉTODO ARQUEOLÓGICO NAS REDES DE MEMÓRIA EM BELÉM}

Para nossa análise, é importante considerarmos o discurso situado historicamente, como uma construção social, diretamente relacionado a aspectos sociais, econômicos e culturais. Isto nos direciona a pensar que um conjunto de enunciados emerge - qualquer que seja sua materialidade, da mídia à ciência -, em determinado período, a partir das condições de possibilidades históricas que o cercam (FOUCAULT, 2008). Nesse jogo, se institui um regime de verdade, isto é, uma série de regras e de posições a serem ocupadas para que se delineiem o dito e o não-dito numa sociedade.

As condições para que apareça um objeto de discurso, as condições históricas para que dele se possa 'dizer alguma coisa' e para que dele várias pessoas possam dizer coisas diferentes, as condições para que ele se inscreva em um domínio de parentesco com outros objetos, para que se possa estabelecer com eles relações de semelhança, de vizinhança, de afastamento, de diferença, de transformação - essas condições, como se vê, são numerosas e importantes. Isto significa que não se pode falar de qualquer coisa em qualquer época. (FOUCAULT, 2008, p. 50)

Antes de passarmos ao discurso midiático nos anos de 2016 e 1966, é preciso dizer sobre qual discurso estamos falando. Não concebemos o discurso desvinculado de genealogias históricas, como se fossem ditos nas mais diversas sociedades de modo apartado de outras relações. Cabe-nos, então, observar os padrões de dispersão e as regularidades de um mesmo objeto, de um mesmo tema, que formam, assim, um discurso. Desse modo, o discurso é formado, diz Foucault (2008, p. 122), por um "conjunto de enunciados que se apoia em um mesmo sistema de formação".

Chamaremos de enunciado a modalidade de existência própria desse conjunto de signos: modalidade que lhe permite ser algo diferente de uma série de traços, algo diferente de uma sucessão de marcas em uma substância, algo diferente de um objeto qualquer fabricado por um ser humano; modalidade que lhe permite estar em relação com um domínio de objetos, prescrever uma posição definida a qualquer sujeito possível, estar situado entre outras performances verbais, estar dotado de uma materialidade repetível. (FOUCAULT, 2008, p. 121)

A análise discursiva, portanto, compreende diferentes materialidades. Em nosso caso, constitui-se pelo conteúdo veiculado em páginas da internet e pelo jornal impresso da década de 1960. Analisaremos enunciados verbais, procurando compreendê-los não apenas do ponto de vista da língua portuguesa, mas também situado numa série de regras do Jornalismo praticado à época e, mais ainda, dentro do caminhar histórico de maneira mais ampla. A partir das proposições de Foucault (2008), a regularidade dos enunciados aponta as redes de 
memórias às quais estão vinculadas. Isso porque a enunciação não é um processo em si. Falamos de um momento em que o sujeito enunciador busca referências, memórias a partir das quais nomeia objetos e se localiza no mundo. Os enunciados analisados podem ser posicionados em séries e, dessa forma, integrarem redes de memórias sobre aniversários de Belém. Redes essas que enunciam a genealogia da cidade e a identidade étnica de quem protagonizou o processo.

Novamente apoiados em Foucault (1999), deixamos de lado a busca pela essência do discurso, ou, citando o autor, do "ponto da criação, a unidade de uma obra, de uma época ou de um tema, a marca da originalidade individual e o tesouro indefinido das significações ocultas" (FOUCAULT, 1999, p. 54). Estamos, na verdade, caracterizando tais discursos como práticas. E mais: práticas descontínuas, que mantêm aparições e regularidades e, então, poderemos "passar às suas condições externas de possibilidade" (Idem, Ibidem, p. 53).

\section{ANÁLISES E RESULTADOS: VINCULAÇÕES DO DISCURSO MIDIÁTICO DE 1966 a 2016}

A escolha pelo portal G1 Pará se deu em função da atenção dada pelo veículo ao tema aniversário de Belém. Braço no campo do webjornalismo da Rede Globo, o G1 é um portal com alta capilaridade, visto que se apoia na presença de seu grupo de comunicação e suas afiliadas em todo o Brasil. Segundo estudo da Agência Nacional do Cinema (Ancine) ${ }^{1}$, a Globo está presente em 5.175 municípios, 92,9\% de um total de 5.570. A emissora também detém a maior audiência: $31,7 \%$ no período matutino, $37,6 \%$ no turno vespertino e $48,2 \%$ à noite, contra $17,8 \%, 15,3 \%$ e 12,5\%, nos três turnos, respectivamente, das segundas colocadas. O G1 Pará fez parte de uma programação maior da TV Liberal, afiliada da Rede Globo no Pará. Nos meses que antecederam a comemoração dos 400 anos da cidade, o grupo lançou marca publicitária específica para a programação. E, na internet, o portal criou uma página exclusiva para reunir esse conteúdo:

${ }^{1}$ TV Aberta no Brasil: aspectos econômicos e estruturais. 
globo.com g1 globoesporte gshow famosos \& etc vídeos

ASSINE JÁ MINHA CONTA E-MAIL $\backsim$ ENTRAR

\section{三 MENU \\ Especial mostra a cultura de Belém nos 400 anos}

Conheça o começo do teatro e do cinema na cidade. Veja quem está na vanguarda da música e literatura

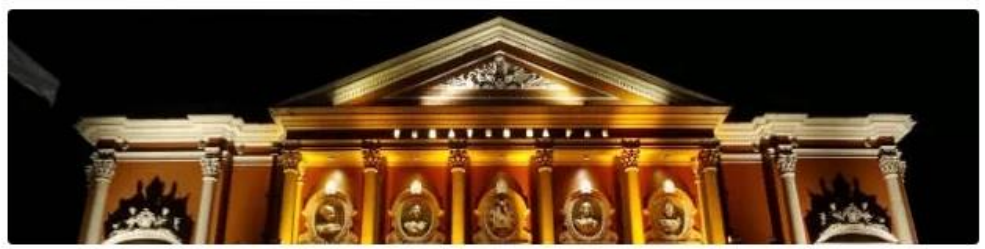

- Veja imagens antigas de Belém do Pará

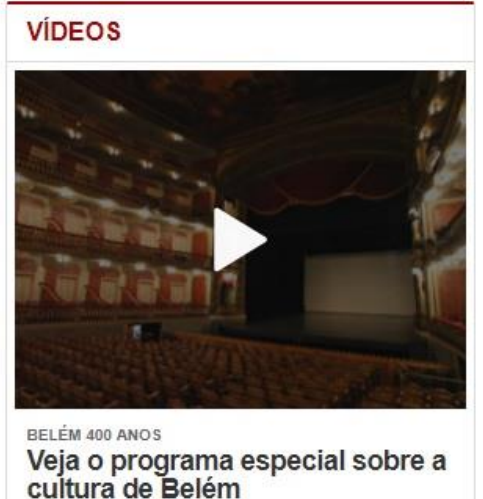

cultura de Belém

Figura 1 - Home da página Belém 400 anos, portal G1 Pará.

Fonte: Reprodução da página do G1 (http://g1.globo.com/pa/para/belem-400-anos) feita pelo autor.

A página reúne reportagens e notícias sobre a programação oficial da prefeitura de Belém referente ao aniversário de 400 anos, bem como concursos promovidos pela TV Liberal como parte da programação, incluindo um que propôs ao público a escolha do "prato símbolo dos 400 anos de Belém”. Em nosso levantamento, computamos 40 notícias, uma entrevista, duas galerias de fotos e cinco reportagens disponibilizadas no portal. Elas se dividiam entre os suportes texto escrito, foto e vídeo (Mais na tabela abaixo). As publicações se iniciam em 12 de janeiro de 2015, quando a prefeitura de Belém lançou a programação oficial da festa, e se encerram em 19 de agosto de 2016, totalizando um período de 19 meses.

Todo o conteúdo se encontra na categoria informativa de gêneros jornalísticos (MARQUES DE MELO, 2010), dentro da qual, consideramos a notícia como um relato objetivo com pelo menos uma fonte de informação, a reportagem como um gênero que vai além da narrativa factual e que exige investigação de causas e efeitos, e a entrevista como gênero centrado numa figura proeminente, no formato de perguntas e respostas na íntegra (MARQUES DE MELO, 2010).

Para melhor esquadrinhar o conteúdo produzido, elaboramos uma tabela que o divide a partir de sua materialidade ou suporte. Assim, temos quatro categorias: páginas cujo conteúdo é composto apenas por texto escrito; páginas que têm apenas fotografias; páginas 
que reúnem texto escrito e fotografia; páginas que têm texto escrito e material audiovisual; e, ainda, páginas que congregam texto escrito, fotografia e audiovisual.

Tabela 1 - Mapeamento de conteúdo portal G1 Pará

\begin{tabular}{|l|c|}
\hline \multicolumn{1}{|c|}{ Suporte } & Quantidade \\
\hline Matéria com texto escrito & 13 \\
\hline Matéria com texto escrito e foto & 29 \\
\hline Matéria com texto escrito, foto e vídeo & 1 \\
\hline Matéria com texto escrito e vídeo & 3 \\
\hline \multicolumn{1}{|c|}{ TOTAL } & $\mathbf{4 6}$ \\
\hline
\end{tabular}

Fonte: Dados obtidos em levantamento próprio

Dentro deste quadro, optamos pela reportagem cujo título é "Veja como foi a fundação de Belém em 1616 e conheça a sua história”. Nossa escolha ocorreu em função desta reportagem extravasar o noticiário factual, visando a explicar as origens históricas da cidade e, por fim, tornando-se uma materialidade que produz sentidos sobre o estar na cidade naquele momento. E mais: a reportagem é uma recorrência no discurso que tem como objetivo apontar uma origem específica para Belém, o período em que foi fundada e seus fundadores. Enunciados que se referem a essa fundação aparecem em diversos recortes, desde notícias veiculadas na imprensa aos discursos científico e artístico.

O texto do portal G1, enquanto reportagem jornalística, está situado no âmbito de uma ordem discursiva midiática (NAVARRO, 2010), o que implica numa certa escrita que gira em torno da verdade. Tal verdade como uma construção apoiada em diversas ideias: a) isenção do jornalista como produtor da notícia; b) a imparcialidade do noticiário; c) o equilíbrio e a neutralidade do texto jornalístico. Uma verdade que, por ser produção humana e resultado de um conjunto limitado de escolhas dentro de um universo de possibilidades, jamais poderia ser neutra. Uma verdade, portanto, que, historicamente construída, não é estanque, é fruto do movimento perpétuo da sociedade em suas variadas dimensões. Assim, podemos falar na busca pelo estabelecimento de um discurso de verdade, como ressalta Navarro (2010, p. 84), "aquele que, ilusoriamente, se estabelece como um lugar de completude dos sentidos".

Dito de outro modo, os aspectos ideológicos e econômicos determinam aquilo que o jornalista pode e deve escrever. É nesse jogo de legitimação e controle em que funciona a ordem discursiva midiática. Essa prática impõe ao fazer jornalístico certa configuração na produção e na veiculação da notícia, que abrange desde a seleção, passa pela forma de organização e chega à sua forma de apresentação. Essa configuração indica, nesse sentido, 
uma hierarquia na seleção, organização e apresentação das notícias. (NAVARRO, 2010, p. 83)

A ânsia pela padronização jornalística, um texto cujo estilo é norteado por uma série de regras e que passa ainda pelo "crivo editorial, que exerce a função de manter determinados padrões nos jornais e nas revistas" (NAVARRO, 2010, p. 83), é parte da construção da verdade. Ainda segundo Navarro (2010), um processo no qual as técnicas básicas do jornalismo, como investigação e apuração, envolvendo entrevistas, análises, fotografias e dados estatísticos, têm por função tornar o profissional do jornalismo o sujeito a produzir notícia na sua verdade.

Apresentadas discursivas que constroem o jornalismo-verdade, passamos à análise da reportagem, que aponta a origem de Belém como derivada da presença portuguesa na região que viria a se tornar Amazônia. O argumento principal é a defesa do território colonial português ao norte. Isso porque outras nações europeias passariam, no século XVII, a se instalar na região. A fundação de Belém se relaciona com a fundação de São Luís como partes de um processo mais amplo de expulsão dos invasores de outras nações europeias, como franceses, holandeses e ingleses. Depois da expulsão francesa em São Luís, a expedição de Francisco Caldeira Castelo Branco partiu rumo ao rio Pará em busca de local apropriado para a fundação de um forte de modo a ocupar a entrada da Amazônia. Estes acontecimentos explicariam as origens da hoje cidade de Belém, segundo a reportagem.

No decorrer da narrativa, que busca percorrer resumidamente a história de Belém até o ano de 2016, há uma série de outras referências: as obras do arquiteto bolonhês Antônio Landi, a igreja da Sé, a Cidade Velha como bairro das mais antigas memórias de Belém, a imigração libanesa ao Pará e a Belle Époque - período de apogeu da economia da borracha com referencial cultural francês. Todas essas referências são estrangeiras, na maior parte memórias europeias. O texto é materialidade em que emergem memórias oficiais do momento da comemoração dos 400 anos, uma vez que busca demonstrar quais as vinculações históricas hegemônicas, apontar quem considera como os legítimos fundadores da cidade e, portanto, seus herdeiros.

$\mathrm{Na}$ época da fundação da cidade a baía era um grande mangue, e o que chamava a atenção era a elevação do terreno, perfeita para a construção de uma base que protegesse a entrada da Amazônia. Um local de difícil acesso, mas que parecia muito com o território onde foi erguida São Luís. (Trecho matéria. Disponível em:

http://g1.globo.com/pa/para/belem-400-anos/noticia/2016/01/veja-como-foifundacao-de-belem-em-1616-e-conheca-sua-historia.html) 
Para nós, a descrição de uma Belém europeia é o dito; o não-dito é o silenciamento da memória indígena e africana na formação da cidade. E, almejando a compreensão das discursividades na mídia, "todo acontecimento pressuporia que fosse desdobrado um saber e um não saber, um mundo e um fim de mundo”, conforme Moulliaud (2012, p. 98).

O acontecimento seria um recurso cujo valor residiria menos no que ele é do que no que não é. $O$ excesso não estaria do lado onde se o deplora bordinariamente (um excesso de informações, de palavras e de imagens). Seria um excesso no não saber.

Em nenhum momento, na reportagem que se propõe a recontar a história de Belém, mencionam-se nações indígenas que compunham o território amazônico e tampouco sobre as guerras, tensionamentos e abusos cometidos por portugueses contra esses povos. Muito menos as estratégias de resistência e negociações que caracterizem esses povos como sujeitos dotados de vontade. Em nenhum trecho, percorrendo esses 400 anos, fala-se sobre africanos escravizados que foram trazidos à força para servir de mão de obra. Na verdade, o fragmento da reportagem citado acima materializa o apagamento das memórias indígenas. Isso porque a área de fundação do forte do Presépio é descrita como "um grande mangue" e que chamava a atenção pela "elevação do terreno", sem mencionar que ali existia um território Tupinambá, grupo que por anos enfrentou a presença portuguesa na região. A esse procedimento chamaremos de interdição (Foucault, 1995), um princípio que compõe as regras a partir das quais o discurso pode circular. E essa exclusão das memórias indígena e africana é a materialização de que, como lembra Foucault (1995, p. 9): "Não se pode falar de tudo em qualquer circunstância, que qualquer um, enfim, não pode falar de qualquer coisa". E essas circunstâncias específicas na elaboração do discurso também regem o discurso na mídia a partir de práticas discursivas:

As séries de interdições impedem, pois, que o discurso seja pronunciado aleatoriamente. Assim, espera-se que o sujeito observe determinadas regras que circunscrevem o lugar de onde fala, a posição que ocupa na sociedade e o que isso implica. Portanto, os sujeitos não são livres para formular qualquer discurso, pois só podem ser formulados os discursos que forem autorizados pelo sistema de relações que regula as práticas discursivas. (NAVARRO, 2010, p. 83)

Como já apontamos em nosso referencial teórico, esses enunciados a compor o discurso sobre o aniversário de Belém não emergem isoladamente. Eles aparecem a partir do momento em que memórias individuais e coletivas se relacionam durante a enunciação. Estes enunciados estão emaranhados numa rede de memórias mais longa. Uma rede que nos 
propomos a investigar de modo a demonstrar como um discurso está relacionado a outras séries discursivas.

Acabamos por observar, então, que o discurso sobre o aniversário de 400 anos de Belém, comemorado em 2016, possui uma importante relação com o aniversário de 350 anos, que ocorreu em 1966. E, ainda mais, uma ligação que pode ser observada no discurso jornalístico dos dois períodos.

Como no ano de 2016, investigamos o discurso jornalístico da década de 1960 e realizamos novamente um recorte - desta vez, optamos por dois dos jornais de grande circulação no período: "O Liberal" e "Folha do Norte". A escolha se deu pela disponibilidade do conteúdo destes jornais no setor de microfilmes da Biblioteca Pública Arthur Vianna, da Fundação Cultural do Pará (FCP). Neles, investigamos o período entre $1^{\circ}$ de janeiro e 13 de janeiro de 1966, quando houve um importante fluxo de notícias, reportagens, crônicas e artigos sobre as comemorações do aniversário de 350 anos de Belém. Encontramos uma série de intersecções entre as duas comemorações separadas por cinco décadas.

Importante lembrar que, no ano de 1966, a ditadura civil-militar (PETIT; CUÉLLAR, 2012) buscava legitimidade entre a população brasileira, sendo que um dos eixos para a condução desse processo eram os jornais. É sabida a censura institucionalizada pelo regime a diversas formas de expressão, inclusive à liberdade de imprensa. Não cabe aqui o debate sobre em que medida as publicações feitas pelos jornais citados refletiam a perseguição política perpetuada pela ditadura ou se havia acordo ideológico com o regime, mas apontamos que, nas páginas dos jornais, diariamente eram publicadas matérias, artigos e colunas em apoio à ditadura. O seguinte trecho é um exemplo: "A Revolução tem fôrça para comandar esta ou aquela solução" (sic). A manchete da primeira página do jornal "A Folha do Norte", edição n ${ }^{\circ}$ 31.827, de 13 de janeiro de 1966, tratava do pleito do general Costa e Silva de ocupar a presidência, dando a ideia de que o regime prosseguiria.

Na semana do aniversário de 1966, houve banquete conduzido pelo prefeito Oswaldo Melo a convidados, como relatado na mesma edição do dia 13, um dia após as comemorações do aniversário, além de missa em homenagem presidida pelo arcebispo Dom Alberto Ramos, apoiador declarado do regime civil-militar (COIMBRA, 2003). Houve ainda parada militar, desfile de escolas de samba, festa aberta à população no teatro São Cristóvão, campeonato de futebol, apresentação da esquadrilha da fumaça, lançamento de músicas comemorativas e concurso carnavalesco que escolheu a "rainha da cidade de Belém". 


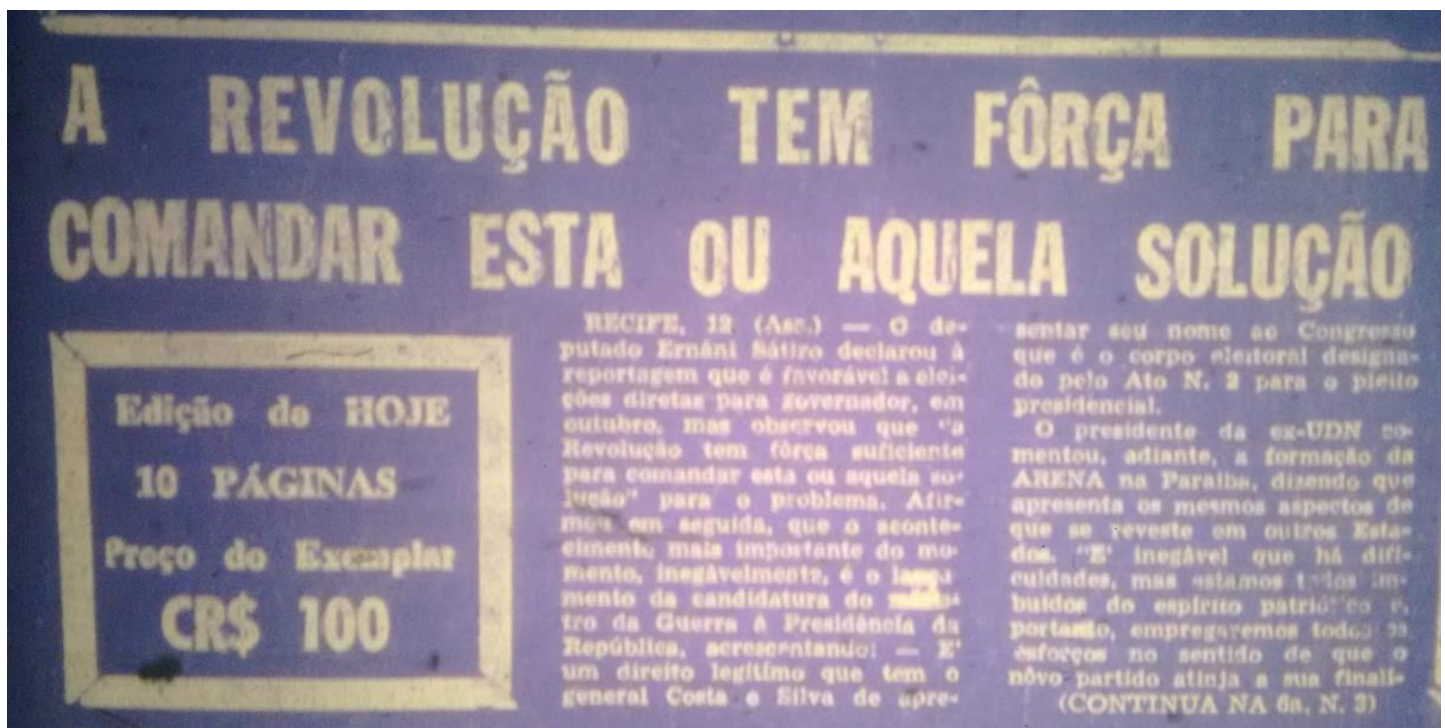

Figura 2 - Primeira página do jornal “A Folha do Norte”, edição n 31.827, de 13 de janeiro de 1966. Fonte: Reprodução de microfilme na hemeroteca da Biblioteca Pública Arthur Vianna

Dentre estas intersecções, funciona uma rede de memórias (FOUCAULT, 2008; GREGOLIN, 2007), na edição do dia 9 de janeiro, do jornal "O Liberal”, que, naquele período, publicava a coluna "Fatos e Curiosidades da História do Pará", de caráter científico, assinada pelo historiador Ernesto Cruz. Na ocasião, ele publicou "Primícias da fundação de Belém (sic)", artigo cujo conteúdo traçava um debate sobre a fundação da cidade. Nele, marcam-se enunciados que, 50 anos depois, reaparecem na reportagem publicada pelo G1 Pará, tais como: a quantidade de soldados e embarcações envolvidas na expedição de fundação, as características geográficas da região, a importância geopolítica à coroa portuguesa, os desafios da jornada.

Além dessas marcas, o principal é o silenciamento de sociedades indígenas e africanos escravizados na formação de Belém. O artigo menciona a presença indígena como elemento secundário da cena da fundação da cidade, como no trecho em que fala sobre um "holandês que estava vivendo numa aldeia de índios, para aprender a língua dos nativos, e ser assim útil aos seus patrícios".

Tanto o artigo de Ernesto Cruz, em 1966, quanto, posteriormente, a publicação do portal G1, possuem regularidades que remontam a textos de cronistas do período colonial. $\mathrm{O}$ primeiro deles é a "RELACION DE LO QUE AY EN EL GRANDE E FAMOSO RIO DE LAS AMAZONAS DESCÚBIERO MEBAMENTE. 1616", memorial escrito por André Pereira, cronista da expedição de Francisco Caldeira Castelo Branco. O segundo é a carta 
escrita pelo arcebispo de Lisboa, à época vice-Rei, enviada ao governador-geral do Brasil, em 4 de setembro de 1616, na qual se refere à correspondência recebida de Caldeira Castelo Branco. Ambos os documentos foram citados no artigo de Ernesto Cruz. Na carta, novamente o "gentio", como traça a narração, é elemento secundário:

(...) e com a armada entrar pelo primeiro braço que aquele rio faz, e navegando por ele TRINTA LEGUAS, escolheu um sítio forte por natureza (onde edificou uma fortaleza) com enseada de fundo bastante para navios de grande porte, e canal muito limpo para poderem entrar, e surgir debaixo da artilharia; e que tem este primeiro braço vinte e cinco leguas de largo todo de ilhas povoado de gentio.

A matéria do portal G1 em 2016, o artigo do jornal "Folha do Norte" de 1966 e os documentos coloniais são dispersões entre três momentos diferentes, produtos historicamente construídos pelos sujeitos de suas épocas. Tais recorrências demonstram a reiteração de enunciados coloniais, mas também suas singularidades. A partir da análise dos enunciados destes três períodos emerge a noção acontecimento, para a qual não há o sujeito fundante, sem uma continuidade temporal e, portanto, sem uma série que possibilite uma linha evolutiva desprovida de tensões e questionamentos. Ora, são períodos distintos, com recortes temporais diferentes, separados por períodos de tempo a partir de uma regularidade de impermanências, isto é, sem uma produção regular. E, por fim, tal análise demonstra a emergência do discurso sobre a fundação de Belém a partir de uma complexa teia de significantes, sem um núcleo do significado do discurso, mas sim em meio a condições de possibilidades históricas. Desta forma, não se trata de uma busca por causas e efeitos, mas sim, como demarca Foucault (2012, p. 53), de "estabelecer as séries diversas, entrecruzadas, divergentes muitas vezes, mas não autônomas, que permitem circunscrever o lugar do acontecimento, as margens de sua contingência, as condições de sua aparição".

Observando a emergência deste discurso, é preciso apontar as condições de possibilidades históricas. Assim, nos perguntamos: a mobilização de diversos setores da sociedade na enunciação do aniversário de Belém ocorreria em quaisquer circunstâncias? O fato de Belém comemorar aniversário de 350 anos e de 400 anos, por serem datas "redondas", que marcam três séculos e meio de existência e depois os quatro séculos da cidade, por si só garantiriam comemorações? Acreditamos que não.

Há, ao redor destas datas "redondas", destas datas que pontuam marcos, um conjunto de fatores e circunstâncias, ou condições que possibilitam suas emergências. Em 1966, como já dito, ainda se perpetua o momento de instabilidade política nacionalmente. Dado o golpe 
civil-militar que destituiu o presidente João Goulart, o novo regime procurava se consolidar a partir de uma agenda positiva repetida exaustivamente na imprensa, se utilizando da censura às críticas, de modo a solapar qualquer atividade política contrária à ditadura. Nesse contexto, a comemoração do aniversário compõe um momento de atualização do discurso colonial, uma vez que devemos visualizar, como em Foucault, o discurso em suas dobras, seus limites e interações com outros discursos. Essa atualização do discurso colonial das elites de outrora na enunciação do aniversário se relaciona com a consolidação do discurso da elite da década de 1960. O processo colonial é reatualizado, naquele momento, como mecanismo de solidificação da ditadura civil-militar.

De maneira semelhante, devemos visualizar o aniversário de 400 anos a partir de sua exterioridade. Os festejos, de maneira planejada, não se dariam em 2016 independentemente das circunstâncias. Naquele ano, o país novamente vivia um momento de instabilidade econômica, política e institucional - na crescente polarização entre os críticos e os apoiadores do governo de Dilma Rousseff (PT), mas não apenas, já que estava em movimento uma agenda conservadora a ser instaurada de maneira mais ampla no Brasil. Uma agenda que ainda inclui impactos nos campos do meio ambiente e da cultura, passando pela economia, por questões trabalhistas, previdenciárias, legais e morais.

Há, então, uma relação possível: em 1966, o discurso colonial reatualizado se relaciona diretamente com a necessidade de consolidação de uma nova elite no poder, um conjunto de enunciados austeros sobre Estado, governo, visão de mundo e relações de poder entre elite e sociedade. Havia também em 2016 uma relação de forças entre grupos antagônicos nacional, estadual e localmente. A atualização do discurso colonial sobre Belém em 2016 era uma forma de manutenção das elites que apoiaram e apoiam a uma agenda conservadora implementada nacionalmente. Assim, tanto em 1966 quanto em 2016, a atualização do discurso colonial na enunciação dos aniversários é uma forma de sustentação do poder das elites de cada momento.

A reiteração de sentidos coloniais na construção de certa Amazônia, a partir de enunciados veiculados em programas de tevê, foi estudada por Dutra (2005). O autor analisou programas veiculados pela Rede Globo sobre a região, observando a construção de uma imagem amazônica, que, a partir de olhar exterior, cria uma região baseada em caráter ambiental, outorgando a seus moradores o título de povos da floresta, responsáveis pela preservação do meio ambiente. Narrativas midiáticas que invocam enunciados construídos durante o período colonial, assim como em reportagens produzidas pela revista Amazônia 
Viva, em Belém, que, ainda, recorrem ao estilo de textos coloniais e da literatura de viagem, romantizando populações tradicionais, como descrito por Rodarte (2017). Materialidades midiáticas que atualizam discursos coloniais em diversas plataformas, tais como o cinejornal na década de 1960, de caráter desenvolvimentista, fazendo renascer sentidos como o vazio demográfico, conforme pesquisa de Santos (2018).

Nesse processo, os modos e as regras de produção do discurso midiático protagonizam o que Foucault chama de interdição, que incide sobre grupos situados fora da ordem discursiva. Pobres, mulheres, periféricos, negros, desempregados, autônomos, gays e lésbicas, pessoas com deficiências e outras populações que constituem a cidade, foram interditados: não tinham o direito de falar sobre o aniversário de 400 anos da cidade, não tinham o direito de comemorar, não tinham o direito de disputar discursivamente aquele espaço. Essa interdição e a visibilização de uma Belém europeia é parte de uma colonialidade do poder (QUIJANO, 2005) a partir da qual as elites da América Latina, herdeiras sociais do período colonial, reatualizam processos de dominação dos descendentes de povos originários e de matriz africana no continente. A comemoração dos 350 anos e, depois, dos 400 anos, tendo como referência o início do processo colonial, portanto, é a legitimação da colonialidade do poder em Belém.

\section{CONSIDERAÇÕES FINAIS}

Neste artigo, realizamos um esforço analítico no intuito de apontar como o discurso midiático, a partir da leitura do portal G1 Pará, rememora, atualiza e invoca o discurso midiático e histórico de 50 anos atrás, nos jornais impressos estudados. E, assim, buscamos mostrar que estes discursos midiáticos sobre o aniversário de Belém atualizam o discurso colonial sobre a fundação da cidade e, mais ainda, o porquê de emergirem exatamente nos momentos históricos descritos e como eles se relacionam e operacionalizam a colonialidade do poder.

Retomamos o conceito de redes de memória (FOUCAULT, 2008; GREGOLIN, 2007), a partir do qual discursos interagem em perpétuo movimento de invocação uns aos outros, para compreendermos o acontecimento jornalístico. Isso porque o relato do fato no jornalismo, a partir de sua relação com o acontecimento discursivo, "desperta e reoferece uma atualidade a acontecimentos passados dos quais reatualiza o paradigma", conforme Moulliaud (2012, p. 91). Portanto, a repetição de enunciados a compor um discurso, do portal G1 Pará 
aos jornais impressos da década de 1960 e, ainda, aos textos de cronistas do período colonial, materializam o conceito das redes de memória.

A verdade é deste mundo; ela é produzida nele graças a múltiplas coerções e nele produz efeitos regulamentados pelo poder. Cada sociedade tem seu regime de verdade, sua política geral de verdade: isto é, os tipos de discurso que ela acolhe e faz funcionar como verdadeiros, os mecanismos e as instâncias que permitem distinguir os enunciados verdadeiros dos falsos, a maneira como se sanciona uns e outros; as técnicas e os procedimentos que são valorizados para a obtenção da verdade; o estatuto daqueles que têm o encargo de dizer o que funciona como verdadeiro. (FOUCAULT, 1995, p. 12)

O que funciona como verdadeiro? A partir de nossa análise, a cidade e sua égide histórica, os antepassados de seus habitantes, seus traços culturais, comportamentais e suas identidades de maneira mais ampla, todas são portuguesas. Essa é a verdade, ou melhor, esse é regime de verdade a que estamos submetidos. Um regime que exclui como verdade a presença indígena e a presença africana. Nesse regime, somos, de alguma forma, europeus. Um regime em que, de alguma maneira, por mais que seja uma pequena parte, descende de uma cidade portuguesa. Essas são as marcas que emergem a partir da análise de enunciados extraídos dos veículos de comunicação em 2016, no aniversário de 400 anos de Belém, e que demonstram suas vinculações históricas ao aniversário de 350 anos na mídia.

Nosso artigo buscou caracterizar essa forma discursiva que vincula a genealogia histórica da cidade ao referencial português, quando mais, europeu, a que já nos referimos como formas oficiais de se comemorar (NEVES; SARRAF, 2017). Um esforço, contudo, que aponta para novos horizontes políticos e teóricos. O principal deles, neste momento, é o cuidado para que a pesquisa acadêmica, ao criticar o apagamento da diversidade étnica da cidade, não recaia no mesmo silenciamento protagonizado pelas elites; que, ao centrar nosso olhar analítico sobre o discurso colonial, mesmo de modo crítico, não atualizemos e repitamos o apagamento de memórias e saberes historicamente subalternizados desde a colonização até os períodos analisados.

Assim, os desafios que se impõem giram em torno do estudo do discurso sobre o aniversário de Belém de modo a encontrar onde estavam e onde estão aqueles que foram marginalizados durante o processo; onde residem suas existências no campo discursivo. A comemoração dos aniversários é um momento de ruptura em que são visibilizadas memórias subterrâneas, "emergem em momentos de crise em sobressaltos bruscos e exacerbados" (POLLAK, 1992, P. 2). Neste momento, “a memória entra em disputa. Os objetos são 
escolhidos de preferência onde existe conflito e competição entre memórias concorrentes" (Idem, ibidem, p. 2).

E, como diz Foucault $(1985,91)$, “onde há poder, há resistência”, devemos visibilizar a maneira pela qual grupos descendentes de povos indígenas e de matriz africana também protagonizaram, às suas maneiras, a disputa pela cidade naqueles momentos em que ocorriam as comemorações dos aniversários. Mas não apenas: é importante saber de que forma grupos marginalizados, grupos situados fora da ordem discursiva oficial, nos mais diversos segmentos, se relacionam com os aniversários de Belém; quais as tensões e enfrentamentos protagonizados; quais as rupturas que emergem nos aniversários das cidades na América Latina, perpetuadas pelos grupos apartados do poder central. Perguntas que nortearam nossa pesquisa de mestrado e que serão respondidas de maneira aprofundada em nova publicação. Em resumo: quais as formas não oficiais de se comemorar o aniversário da cidade?

\section{REFERÊNCIAS}

ANCINE. TV Aberta no Brasil: aspectos econômicos e estruturais. Autoria: Bruna Fontes Roppa e Alex Patez Galvão. Observatório Brasileiro do Cinema e do Audiovisual. 2015. Disponível em:

<https://oca.ancine.gov.br/sites/default/files/repositorio/pdf/Estudo_TVAberta_2015.pdf〉. Acesso em 15 ago. 2018.

COIMBRA, Oswaldo. Dom Alberto Ramos mandou prender seus padres: a denúncia de Frei Betto contra o Arcebispo do Pará em 1964. Belém: Paka-Tatu, 2003.

DUTRA, Manuel Sena. A natureza da TV: uma leitura dos discursos da mídia sobre a Amazônia, biodiversidade, povos da floresta. Belém: Naea, 2005.

FOUCAULT, Michel. A Ordem do Discurso. 5a ed. São Paulo: Editora Loyola, 1999.

FOUCAULT, Michel. A Arqueologia do Saber. $7^{\text {a }}$ ed. Rio de Janeiro: Editora Forense Universitária, 2008.

FOUCAULT, Michel. História da Sexualidade I: a vontade de saber. Rio de Janeiro: Graal, 1985.

FOUCAUlT, Michel. O Olho do Poder. In: Microfisica do Poder. Org. e Trad. Roberto Machado. Rio de Janeiro: Edições Graal, 1995.

GREGOLIN, Maria do Rosário. Formação discursiva, redes de memória e trajetos sociais de sentido: mídia e produção de identidades. In: BARONAS, Roberto Leiser (Org.). Análise do discurso: apontamentos para uma história da noção-conceito de formação discursiva. São Carlos: Pedro e João, 2007. 
HALBWACHS, Maurice. A Memória Coletiva. São Paulo: Centauro, 2013.

MARQUES DE MELO, José. Gêneros Jornalísticos: conhecimento brasileiro. In: MARQUES DE MELO, José; ASSIS Francisco (Orgs). Gêneros Jornalísticos no Brasil. São Bernardo do Campo: Universidade Metodista de São Paulo, 2010.

MOUILLAUD, Maurice. (2002), O jornal: da forma ao sentido. 3. ed. Brasília, Editora Universidade de Brasília, 2012.

NAVARRO, Pedro. Uma definição da ordem discursiva midiática. In: Milanez, Nilton \& Gaspar, Nádea (orgs.). A (des)ordem do discurso. São Paulo: Contexto, 2010.

NEVES, Ivânia dos Santos. EtniCidades: os 400 anos de Belém e a presença indígena. Moara, Belém, n. 43, p. 26-44, jan./jun. 2015.

PÊCHEUX, M. A Análise de Discurso: três épocas (1983). In: GADET, F.; HACK, T. (org.). Por uma análise automática do discurso. Uma introdução à obra de Michel Pêcheux. Campinas: Ed. Unicamp, 1997.

PETIT, Pere; CUÉLLAR, Jaime. O golpe de 1964 e a instauração da ditadura civil-militar no Pará: apoios e resistências. Est. Hist., Rio de Janeiro, vol. 25, nº 49, 2012.

POLLAK, M. Memória e identidade social. Estudos Históricos, Rio de Janeiro, v. 5, n. 10, p. 200-212, 1992.

QUIJANO, Anibal. Colonialidade do poder, Eurocentrismo e América Latina. In: QUIJANO, Anibal (Org.). A colonialidade do saber: eurocentrismo e ciências sociais: perspectivas latino-americanas. Buenos Aires: CLACSO, 2005. p. 117-142.

RODARTE, Lídia Karolina de Sousa. A Amazônia codificada: a configuração narrativa da comunicação institucional. Dissertação (Mestrado em Ciências da Comunicação). 2017. 148 p. Universidade Federal do Pará, Belém, 2017.

SANTOS, Rodrigo Wallace Cordeiro dos. Pioneiros e duendes: desenvolvimento e integração da Amazônia a partir dos filmes documentários de Jean Manzon. 2018. 103 f. Dissertação (Mestrado em Ciências da Comunicação) - Universidade Federal do Pará, Belém, 2018.

SARRAF, Moisés Taate Alves; NEVES, Ivânia dos Santos. Aniversário de 400 anos: um estudo comparativo entre as comemorações de São Luís (MA) e Belém (PA) nos meios de comunicação. In: COLÓQUIO INTERNACIONAL MÍDIA E DISCURSO NA AMAZÔNIA, 3., 2017, São Luís. Anais... São Luís: EDFUMA, 2017. p. 725-734.

\section{Referências webgráficas}

G1 PA. Belém 400 anos. G1, [on-line], jan. 2016b. Pará. Disponível em: <tinyurl.com/y5jksusn>. Acesso em: 15 ago. 2018. 
G1 PA. Veja como foi a fundação de Belém em 1616 e conheça sua história. G1, [on-line], 9 jan. 2016c. Pará. Disponível em: <tinyurl.com/y4ptgv3d>. Acesso em: 15 ago. 2018.

\section{Referências hemerográficas}

FOLHA DO NORTE. Belém: Folha do Norte, 13 jan. 1966a.

O LIBERAL. Belém: Organizações Romulo Maiorana, 9 jan. 1966a.

Original recebido em: 12 de julho de 2018

Aceito para publicação em: 01 de maio de 2020

Moisés Sarraf

Doutorando do Programa de Pós-Graduação em Memória Social (PPGMS), da Universidade Federal do Estado do Rio de Janeiro (Unirio), linha de pesquisa Memória e Patrimônio. Mestre em Comunicação pelo Programa de Pós-Graduação Comunicação, Cultura e Amazônia (PPGCOM) da Universidade Federal do Pará (UFPA) e graduado em Comunicação Social, habilitação em Jornalismo, pela mesma instituição.

\section{Ivânia dos Santos Neves}

Doutora em Linguística, na área de Análise do Discurso (UNICAMP). Professora Titular da Universidade Federal do Pará (UFPA), onde atua no Instituto de Letras e Comunicação (Graduação em Letras) e no Programa de Pós-Graduação em Letras (Mestrado/Doutorado).

\section{(2) $\odot \otimes \odot$}

Esta obra está licenciada com uma Licença

Creative Commons Atribuição-NãoComercial-CompartilhaIgual 4.0 Internacional 